Hydrology and Earth System Sciences, 7(3), 283-296 (2003) C EGU

\title{
Review of recent advances in index flood estimation
}

\author{
D. Bocchiola, C. De Michele and R. Rosso \\ Hydraulic, Environmental, Roadways and Surveying Engineering Department (DIIAR), Politecnico di Milano, 32 Piazza Leonardo da Vinci, I-20132 Milano, Italy \\ Email for corresponding author: daniele.bocchiola@polimi.it
}

\begin{abstract}
Index flood estimation for regional flood frequency analysis needs to be based on the information available. The most appropriate method depends on the specific application and its choice requires a problem-oriented analysis. This paper presents a simple theoretical framework to deal with index flood estimation for a specific river site. The methodological approaches available for the purpose are reviewed. For each, the information required is specified and the reliability of the estimate, particularly desirable in risk analysis and management, is discussed. Where flood observations are lacking, indirect estimation must be undertaken using scenarios including those commonly met in hydrological practice; generally, these depend on the amount and type of information available. For each scenario, the methodologies are outlined, in order of the expected degree of complexity. After a guided analysis, an investigator can adopt the method providing the best tradeoff between effort in collecting and handling data and the resultant reliability which can be expected.
\end{abstract}

Keywords: direct and indirect methods, index flood estimation, reliability, scenarios.

\section{Introduction}

Flood frequency estimation is fundamental in both engineering science and engineering hydrology since Fuller (1914) approached the temporal variability of flood flows of extremely high return periods. Indeed, many of the advances in the statistical theory of extreme values may be attributed to successful attempts to approach this problem using a coherent mathematical framework (Hazen, 1914; Fréchet, 1927; Fisher and Tippet, 1928; Gnedenko, 1943; Jenkinson, 1955; Gumbel, 1958; Leadbetter et al., 1983; Hosking and Wallis, 1997; Ramachandra Rao and Hamed, 2000). In the last 30 years, effective procedures have been established for flood estimation in individual rivers for large geographical areas, included the possibility of merging relationships from different rivers in a region into a unified probability model (Committee on Techniques for Estimating Probabilities of Extreme Floods, 1988). Furthermore, catchment dynamics had to be incorporated in statistical models to obtain reliable estimates (Eagleson, 1978; Salas et al., 1994). The statistical prediction of design floods by regionalisation was pioneered by Darlymple (1960), who established the conceptual basis of the index flood method. This requires a two-step procedure. The first step requires the identification of a homogeneous region where a common probability model of maximum annual floods can accommodate normalised flow figures; this includes the search for an area of influence where flood data series are likely to be homogeneous with that for a specified river site. The second step involves the search for the appropriate index flood estimator at the particular river site. The major research effort was directed towards introducing objective criteria to address the first step, that is, seeking criteria to aggregate flood information from different river gauges. A somewhat minor effort was devoted towards estimating the index flood, still affected by a large degree of uncertainty due to a business-as-usual empirical approach. The estimation of the index flood is crucial to design flood prediction and it requires the merging of concepts of statistical and physical hydrology to reduce the present uncertainties. The high variability of index floods in different river basins, and throughout the river network of a given catchment, reflects hydrological diversity encompassing river geomorphology, basin land use, geology, lithology and micro-climate. This can lead to non-trivial difficulties in the index flood estimation exercise, so large uncertainties may be introduced in the estimated flood quantiles.

Index flood estimation may be constrained by the data requirements for the application of a particular procedure. 
Also, the reliability (that is, the complement of acceptable risk) associated with the statistical estimates in a specific application, must be assessed because the degree of complexity may differ from one method to another. This review presents a general framework for index flood estimation at a river site using a two-fold approach, taking into account data availability as well as a problem-oriented perspective, conceptually applicable to any case study. Following a review of methods available for index flood estimation, their main advantages and disadvantages are considered and possible scenarios are described, taking data availability into account. These summarise the situations most commonly met by investigators when they try to estimate index flood value at a given river site in an homogeneous region, thus applying a regional approach. For each of these cases, a reference framework is provided to help the investigator in seeking the most appropriate index flood estimate.

\section{General remarks on index flood estimation}

The index value of maximum annual flood peak varies according to different methodologies. As an example, Darlymple (1960) and Hosking and Wallis (1993) used the observed sample mean as estimator of the index flood, Robson and Reed (1999) suggested the observed median (middle ranking value in the series of annual maximum flood), while Sveinsson et al. (2001) propose, as index flood, the location parameter determined on a site to site basis. In the framework of the Flood Evaluation (VAPI) project, carried out by the National Group for Prevention from Hydrological Disasters (GNDCI) supported by the National Research Council (CNR) of Italy, flood peak estimation guidelines were provided for the whole of Italy and the index flood is represented by the expected value of the maximum annual flood peak (De Michele and Rosso, 2001) $q_{\text {index }}=E[Q]$.

Hereinafter, index flood estimation at a given site is the methodology used to assess the average value of the local maximum annual flood peak distribution, provided the basin lies in a homogeneous region. Depending on the information available, index flood estimation may be approached using different methods (Fig. 1), The 'best' estimator can optimise some criterion, such as minimum variance or efficiency (Kottegoda and Rosso, 1997, 242-244). The procedure can arise either from the most reliable method, or from a combination of those available, each weighted by the inverse of its estimation variance. Here, the variance of the $q_{\text {index }}$ is determined to provide a quantitative reliability criterion for the choice of the best methodology. As a first step, one has to decide whether to use direct or indirect methods. Direct methods use information on maximum annual flood peak discharges at the station of interest, deduced from a series of observations of flow depth through some stage-discharge relationship. For unmeasured sites close to an impoundment facility, such as a dam or a reservoir with monitoring of the outflow, the time series of inflow discharge can be assessed by inverse reservoir routing (see e.g. Chow et al., 1988, p. 245 and Bras, 1990, p. 475). In index flood assessment, indirect methods incorporate other hydrological information, such as rainfall, abstraction and the geo-morphological features of the basin.

\section{A review of the available methodologies for index flood assessment}

\section{DIRECT METHODS}

\section{Estimation from maximum Annual Flood Series (AFS)}

If, at a particular river site, a $n$ '-year maximum annual flood peak series of measurements is available, the index flood can be estimated as the mean of sample data $q_{1}^{\prime}, \ldots, q_{n}$,

$$
\hat{q}_{\text {index }}=\hat{\bar{q}}_{A F S}=\frac{\mathbf{1}}{n}, \sum_{i=\mathbf{1}}^{n^{\prime}} q_{i}^{\prime},
$$

where the symbol $\wedge$ represents the estimated value. The standard error of estimate is

$$
\sigma_{\hat{q}_{\text {index }}}=\sqrt{\frac{\mathbf{1}}{n^{\prime}\left(n^{\prime}-\mathbf{1}\right)} \sum_{i=1}^{n^{\prime}}\left(q^{\prime}{ }_{i}-\hat{q}_{\text {index }}\right)^{\mathbf{2}}} .
$$

These errors reduce with increasing sample size. Then, for a given level of significance $a$, the $100(1-a / 2) \%$ level confidence intervals are $\hat{q}_{\text {index }} \pm \Phi^{-1}(1-a / 2) \sigma_{\hat{q}_{\text {inder }}}$, where $F^{-1}($.$) is the standard normal quantile with probability of$ exceedance $a / 2$. The limits $\hat{q}_{\text {index }} \pm \sigma_{\hat{q}_{\text {index }}}$ are also called sigma bounds and correspond to an $84 \%$-level of confidence.

\section{Estimation from Partial Duration Series (PDS)}

If $n$ "-year flood peak data are available for a given river site, one can estimate the index flood from the mean of the flood peaks over a threshold (POT) series, $q^{\prime \prime}{ }_{1}, \ldots, q{ }^{\prime \prime}{ }^{\prime \prime}$, also referred to as the "partial duration series" or PDS (Chow et al. , 1988). One computes

$$
\hat{\bar{q}}_{P D S}=\frac{1}{n^{\prime \prime}} \sum_{i=1}^{n^{\prime \prime}} q^{\prime \prime}{ }_{i}
$$

with a standard error of estimate of 


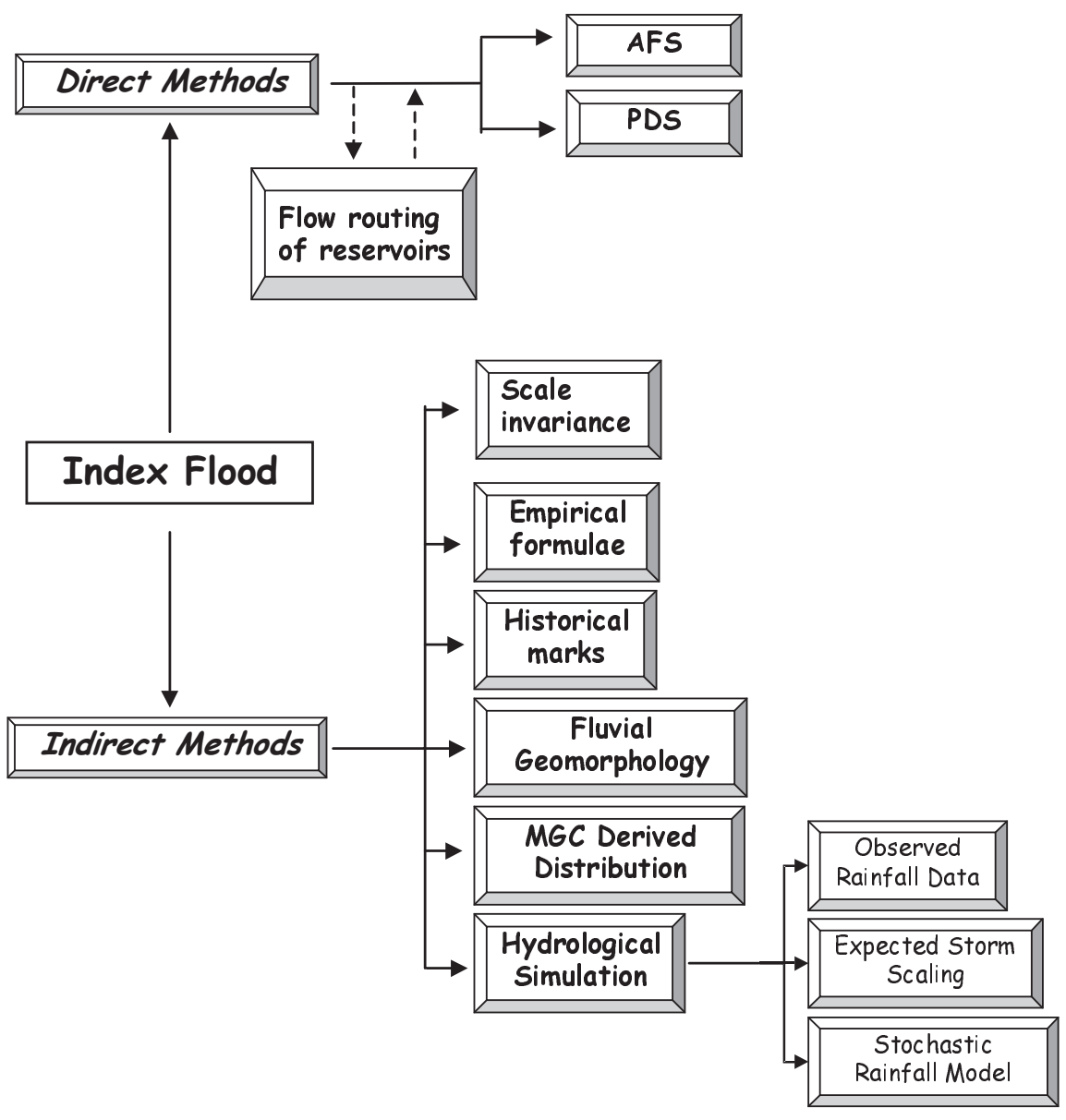

Fig. 1. A classification of direct and indirect methods for index flood estimation at a given river site. AFS is Annual Flood Series, PDS is Partial Duration Series and MGC is Modified Geomorpho-Climatic method. Dashed lines are referred to eventual flow routing of reservoirs

$$
\sigma_{\hat{\bar{q}}_{P D S}}=\sqrt{\frac{1}{n^{\prime \prime}\left(n^{\prime \prime}-1\right)} \sum_{i=1}^{n^{\prime \prime}}\left(q^{\prime \prime}{ }_{i}-\hat{\bar{q}}_{P D S}\right)^{2}} .
$$

The index flood is associated with the mean of flood peaks of Eqn. (1) through the rate of occurrence $\lambda$ of the peaks over the threshold and the parameters of the PDS growth curve. For the case of GEV distribution for the maximum annual flood peaks, well suited for the estimation of growth curves in Italy (De Michele and Rosso, 2001; Bocchiola et al. 2003) one can show it descends from the Generalized Pareto law for the flood peaks over the threshold series if these occur as a Poisson process (Brath et al., 1996; Kottegoda and Rosso, 1997, p. 450). Accordingly, the index flood is given by

$$
\hat{q}_{\text {index }}=\frac{1}{\varepsilon+\frac{\alpha}{k}\left(1-\frac{\lambda^{k}}{1+k}\right)} \hat{\bar{q}}_{P D S} .
$$

Eqn. (5) gives the value of $q_{\text {index }}$ for the given mean of the PDS, $\hat{\bar{q}}_{P D S}$, mean annual rate $\lambda$ of PDS occurrence, and regional GEV parameters $\varepsilon, \alpha$ and $k$ (Brath et al., 1996). In writing Eqn. (5), it is assumed that the latter are properly estimated i.e. their estimation variance can be neglected with respect to that of index flood (for an insight into the estimation variance of the GEV parameters with L-moments technique, see Hosking and Wallis, 1993).

Also, one can evaluate the standard error of the $q_{\text {index }}$ estimation from that of the estimated mean of the PDS as given by Eqn. (3). This is given by

$$
\sigma_{\hat{q}_{\text {index }}}=\sigma_{\hat{q}_{P D S}} \frac{\lambda^{-k}}{k(1+k)} \sqrt{\left(\Gamma(1+2 k)-\Gamma^{2}(1+k)\right) \cdot(1+2 k),}
$$

where $\Gamma$ is the Gamma Function (e.g. Kottegoda and Rosso, 1997, p. 208). This method is more efficient than the previous one (AFS) for small sample size $n$ ' and therefore it can be used when the expected estimation variance in 
Eqn. (6) is lower than for the AFS approach, in Eqn. (2). The PDS threshold is defined so that there is stochastic independence between flood events. A statistical test for independence can be performed accordingly. As a rule of thumb, the mean annual rate of PDS occurrence should not exceed $3-4$.

\section{INDIRECT METHODS}

\section{Scale invariance of index flood}

Maximum annual flood peaks in homogeneous regions are characterised by statistical scale invariant properties with respect to drainage areas, $A$ (e.g. Gupta et al., 1994; Robinson and Sivapalan, 1997). Considering the first order moment of the flood peaks distribution, $q_{\text {index }}$ this yields

$$
\hat{q}_{\text {index }}(A)=q_{\text {index }}(1) A^{m},
$$

where $m$ is a scaling exponent and $q_{\text {index }}(1)$ is the index flood associated with an unit area, both calculated by a multiple regression of the logarithmic transformed sample mean, $\log \left(q_{\text {index }}\right)$, versus the logarithmic transformed values of drainage area $\log (A)$, in an homogeneous region. The scale invariance is usually valid over a range of scales (or areas), determined from observations (De Michele and Rosso, 2002). An estimation of index flood can, therefore, be provided by Eqn. 7, applied to the area of the basin investigated. The estimation variance of the resultant value depends on the properties of the homogeneous region and can be assessed by the coefficient of determination $R^{2}$ of the regression as $\sigma_{\hat{q} \text { index }}^{2}=\sigma_{\text {qindex,s }}^{2}\left(1-R^{2}\right)$, where $\sigma_{\text {qindex }, s}^{2}$ is the variance of the observed sample of $q_{\text {index }}$ in the homogeneous region, eventually estimated from the observations. The consistency of the estimate of index flood in an ungauged basin thus obtained can be checked by verifying whether the river channel can actually convey the estimated discharge without overflowing. In case of an overflow, a check must be made on the consistency of the return period of the estimated $q_{\text {index }}$ (depending on the flood frequency distribution, but usually ranging between two and three years) and that of the observed episodes of overflowing. If there is no coincidence between the two return periods, the estimation of index flood must be reconsidered on the basis of the observed fluvial morphology (see the method of historical flood marks).

\section{Empirical formulae}

Due to their simplicity, empirical formulae are frequently used to estimate the index flood (see e.g. NERC, 1975 and, for an application of the method to the Italian catchments,
Brath et al., 1999; Bocchiola et al., 2000). These link $q_{\text {index }}$ to catchment characteristics such as climatic indexes, geolithologic and geopedologic parameters, land coverage, geomorphic parameters and anthropic forcing. Often, such formulas are calibrated through a multiple regression of the logarithmic transformed sample mean, $\log \left(q_{\text {index }}\right)$, versus the logarithmic transformed values of the parameters. If $N$ parameters are considered, the formulae have the following structure:

$$
\hat{q}_{\text {index }}=\mathrm{const} \prod_{i=1}^{\mathrm{N}} X_{i}^{n_{i}},
$$

where the constant, const, and the exponents, $n_{i}$, are estimated from observed $q_{\text {index }}$ data in gauged basins in an homogeneous region. Notice here that the scale invariance previously mentioned is, to some extent, a particular type of empirical formula, where the only parameter is the drainage area $A$. One has to consider a statistically significant number of regression parameters, to quantify the reliability and the robustness of the statistical model. The robustness of the formulae so obtained can be tested via a "jackknife" or "bootstrap" procedure ( Efron and Tibshirany, 1993).

The estimation variance can be assessed as in the previous case of scale invariance and, again, depends on the features of the homogeneous region. Even though these formulae can explain a high fraction of the variability of the logarithmic transformed of $q_{\text {index }}, \log \left(q_{\text {index }}\right)$, the explained variance of $q_{\text {index }}$ can be very variable. The uncertainties related to the empirical formulae are seldom negligible and the errors can reach $\pm 100 \%$ of the observed values (for a study carried in northern Italy, see Bocchiola and De Michele, 2000; Bocchiola et al ., 2000). Therefore, their use should be limited to cases where the expected estimation variance is lower than, or at least comparable to, that from other methodologies.

\section{Estimation from historical flood marks}

The analysis of historical floods considers intensive flood events (catastrophic floods), observed or documented, characterised by a flood peak over a threshold, $q_{i}$. The threshold is determined according to the hydraulic capacity of the river channel at the site under consideration. As an example, the AVI project (CNR-GNDCI, 1998) representing the Italian Catalogue of Catastrophic Floods, has mapped the flooded river sites in Italy during the last century (from 1900 to 1996). If $n_{t}$ outcomes occurred in $n$ ' years for the flood threshold $q_{t}$, the expected frequency of exceedance of this threshold can be estimated as $\operatorname{Pr}\left[q \geq q_{t}\right]=\left(n_{t}+1\right) /(n+1)$ (Kottegoda and Rosso, 1997, p. 425). Accordingly, the return period of $q_{t}$ is 


$$
\hat{T}_{q_{t}}=\frac{1}{\operatorname{Pr}\left[q \geq q_{t}\right]}=\frac{n^{\prime}+1}{n_{t}+1} .
$$

The index flood is given as

$$
\hat{q}_{\text {index }}=\frac{q_{t}}{x_{\hat{T}_{q 1}}} \text {, }
$$

where $x_{\hat{T}_{t}}$ is the $\hat{T}_{q_{t}}$-years growth factor, or dimensionless flood quantile, computed via the regional probability distribution. The search for outcomes of the historical flood over the threshold series ( $t$-PDS) needs to account only for those outcomes corresponding to flood episodes when the hydraulic capacity of the river channel is exceeded. One must neglect outcomes caused by breaches in embankments, channel obstructions, as well as by engineering works. To investigate the nature of a specific outcome, one should draw the water profile, considering at least steady flow, for $q_{i}$. This method is suggested for those river sites located at historic spots, such as long-term urbanised catchments or river channels controlled by civil facilities, such as road and railway crossings, covered channels and embankments. The sigma bounds of the return period, $\hat{T}_{q_{t}}$, as estimated via Eqn. (9) are

$$
\hat{T}_{q_{t}} \pm \sigma_{\hat{T}_{q_{t}}}=\frac{n^{\prime}+1}{n_{t}+1 \mp \sqrt{\frac{\left(n^{\prime}-n_{t}\right)\left(n_{t}+1\right)}{n^{\prime}+2}}},
$$

showing that the method features increasing uncertainty with decreasing frequency of the outcomes. The sigma bounds and the corresponding estimation variance of the index flood are easily found from those of $\hat{T}_{q_{t}}$ by coupling Eqns.(10) and (11).

\section{Fluvial geomorphology methods based on bankfull discharge}

This method is similar to the previous one but involves a larger amount of uncertainty. Here, the index flood is estimated, using the concept of bankfull discharge, $q_{b f}$, defined as the discharge at which channel maintenance is most effective, that is, the discharge which corresponds to the 'average' morphological characteristics of the channel (Dunne and Leopold, 1978; Savenije, 2003). According to Leopold et al. (1964), Dunne and Leopold (1978) and Leopold (1994), the return period of bankfull discharge, $q_{b p}$ ? is approximately equal to 1.5 years, $\hat{T}_{b f}=1.5$ years .

The index flood is

$$
q_{\text {index }}=\frac{q_{b f}}{x_{1.5}}
$$

where $x_{1.5}$ is computed from the proper regional probability distribution. Note that this method requires that the natural river course is neither modified by engineering works nor constrained by tectonic controls. Therefore, application is confined to a rather small number of practical situations, because rarely are those two conditions satisfied. Conversely, the deviations from natural fluvial geomorphology can provide an insight into the anthropogenic forcing of the river system. The estimation variance of this approach depends on the reliability of the basic hypothesis, i.e. a 1.5-years return period of the bankfull discharge. Estimation of the average return period into an homogeneous region and its sigma bounds requires the analysis of the channel morphology and hydraulic conductivity at some gauged sites, coupled with the corresponding flood frequency distribution. The results so obtained could be extended to the ungauged sites of interest located in the homogeneous region and Eqn. (12) can be used to assess sigma bounds of estimated index flood.

\section{Derived distribution approach using the Modified Geomorpho-Climatic method}

This method is based on the derived distribution approach. The statistics of the flood peaks are derived, as probabilities, from the statistics of storms, using a description of the physical phenomena involved in flood generation. This requires a stochastic rainfall model and a rainfall-runoff model describing the routing of flood peak. Starting from the pioneering work of Eagleson $(1972,1978)$, derived distribution models were introduced by Hebson and Wood (1982, 1986), Wood and Hebson (1986), Cordova and Rodriquez-Iturbe (1983, 1985), Brath et al. (1992), Raines and Valdes (1993), among others. The modified geomorphoclimatic (MGC) method introduced by Bacchi and Rosso (1988) and further developed by Adom et al. (1989) and Brath et al. (1992) is considered here, because it is specially oriented towards the estimation of statistical floods moments. This is a modification of the geomorphoclimatic method introduced by Rodriguez-Iturbe et al. (1982) and derives, using a second-order secondmoment technique, the first two statistical moments of the flood peaks (the mean and variance), instead of the full probability distribution of flood peaks. Assuming that rainfall intensity and storm duration are independent and exponentially distributed variates for a storm episode, the MGC method describes runoff production using the SCSCN method (Soil Conservation Service, 1973, 1986) assuming negligible initial abstraction $(c=0)$. The flood response of the river network is assessed using the gamma GIUH (Rosso, 1984). Accordingly, the MGC method provides the mean of the flood peak over a threshold series 
as

$$
\begin{gathered}
\hat{\bar{q}}_{P D S}=A \mu_{i} \eta\left\{\left[\left(1-e^{-\chi}\right)\left(1+K^{2}\right)-K^{2} \chi e^{-\chi}\left(1+\frac{\chi}{2}\right)\right] .\right. \\
{\left[1+3 K^{2}\left(1-\eta^{2}\right)\right]_{+}} \\
\left.+K^{2}(2-\eta)\left[e^{-\chi}(1+\chi)-1\right]\right\}
\end{gathered}
$$

where

- $A$ : is the catchment area;

- $\mu_{i}$ : is the mean of storm intensity; it is the parameter of the exponential distribution used to describe the rainfall depth;

- $\eta$ : is the dimensionless factor $\eta=\mu_{P} /\left(\mu_{P}+S\right)$ the ratio between the mean of storm depth, $\mu_{P}$ (the product of the mean of storm intensity, $\mu_{i}$, and the mean of storm duration $\left.\mu_{t}\right)$ and the term $\left(\mu_{P}+S\right)$, where $S$ is the maximum soil potential retention, parameterised by the SCS-CN method;

- $\chi$ : is the geomorphoclimatic factor which represents the ratio between the mean storm duration, $\mu_{t}$, and the lag time of the basin, $t_{L}, \chi=\mu_{t} / t_{L}$; and

- $K$ : is the areal reduction factor of storm rainfall, $0 \leq K^{2} \leq 1$.

The estimated $\hat{\bar{q}}_{P D S}$ is used to estimate $q_{\text {index }}$ via Eqn. (5). Actually, this method involves considerable effort in the assessment of average rainfall properties, $\mu_{t}$ and $\mu_{i}$ and the rate of occurrence $\lambda$. On a theoretical basis, such properties should be inferred directly from the analysis of rainfall data at the finest possible resolution. The huge amount of data required for this procedure makes it unwieldy, particularly when dealing with several basins, so such parameters are often deduced indirectly from the maximum annual rainfall properties (Bacchi and Rosso, 1988; Brath et al., 1992). Such an approach adds uncertainty to index flood estimation by the MGC method. Due to non-linearity of the rainfallabstraction-runoff modelling involved in the method, an easy assessment of its reliability cannot be made. However, if a validation of the approach effected for some gauged catchments in an homogeneous region, prior to its application to ungauged basins, the related coefficient of determination $R^{2}$, can provide a first guess for the estimation variance, as in the case of the empirical formulas. Notice here that the SCS-CN method requires a definition of the Antecedent Moisture Condition (AMC) for the event. In the context of the MGC method, such a parameter has to represent the "average" moisture conditions verified for extreme (i.e. maximum annual) flood events in the region being investigated. The MGC method requires data acquisition and handling for precipitation, soil properties and basin morphology, thus involving considerable complexity and, hence, time. A flow-chart in Fig. 2 shows the necessary features to be considered when using the MGC method for index flood estimation.

\section{Hydrological simulation}

The formulation of a flood hydrological model, lumped or distributed, describing the rainfall-runoff process for severe events, enables reconstruction of a sequence of flood events at a particular river site (Boughton and Droop, 2003). If one or more rainfall-runoff events are available (hyetograph and the corresponding hydrograph), they can be used in model calibration and validation, often required prior to its use. In principle, one should estimate the model parameters from the physical characteristics of the system while improving the spatial resolution of the model to describe the heterogeneity of the different system components: soil, vegetation, topography and rainfall. Three approaches for hydrological simulation are now described, depending on the availability of input data.

Simulation using observed rainfall input. In this case, the rainfall input is observed continuously in time for a consistent number of years, $n$ ”. The index flood is estimated via hydrological simulation calculating the hydrographs correspondent to the rainfall input. From these, the series of maximum annual flood peaks, $q{ }^{\prime}{ }_{1}, \ldots, q{ }^{\prime}{ }_{n}$, is extracted. The index flood can be estimated either as the mean of sample data using Eqn. (1), or by PDS using Eqns.(3) - (5). As the hydrological model is continuous in time, it requires the continuous revision of the soil moisture or its evaluation at the beginning of the storm event. This method is well assessed with numerous practical applications (Cameron et al., 1999 and references therein), even though it requires great effort to collect and work out the rainfall time series at fine temporal resolution (e.g. hourly data or less, for basins with short response times). The reliability of the method depends on the suitability of the rainfall abstraction and runoff models. The methodology must be validated in gauged basins in an homogeneous region, where direct estimates of index floods are available and the reliability of the method can be assessed by comparing the direct with the indirect estimates. One has to consider the bias in estimation, if any and in the estimation variance. Also, the sensitivity of the final estimate can be tested in relation to the number of available years, i.e. the amount of simulated flood events, for both AFS and PDS approaches.

Simulation based on expected storm scaling. When the observed rainfall time series is not available for a river basin, the Depth-Duration Frequency curve, DDF (Burlando and Rosso, 1996), can be used to represent a rainfall storm for a 


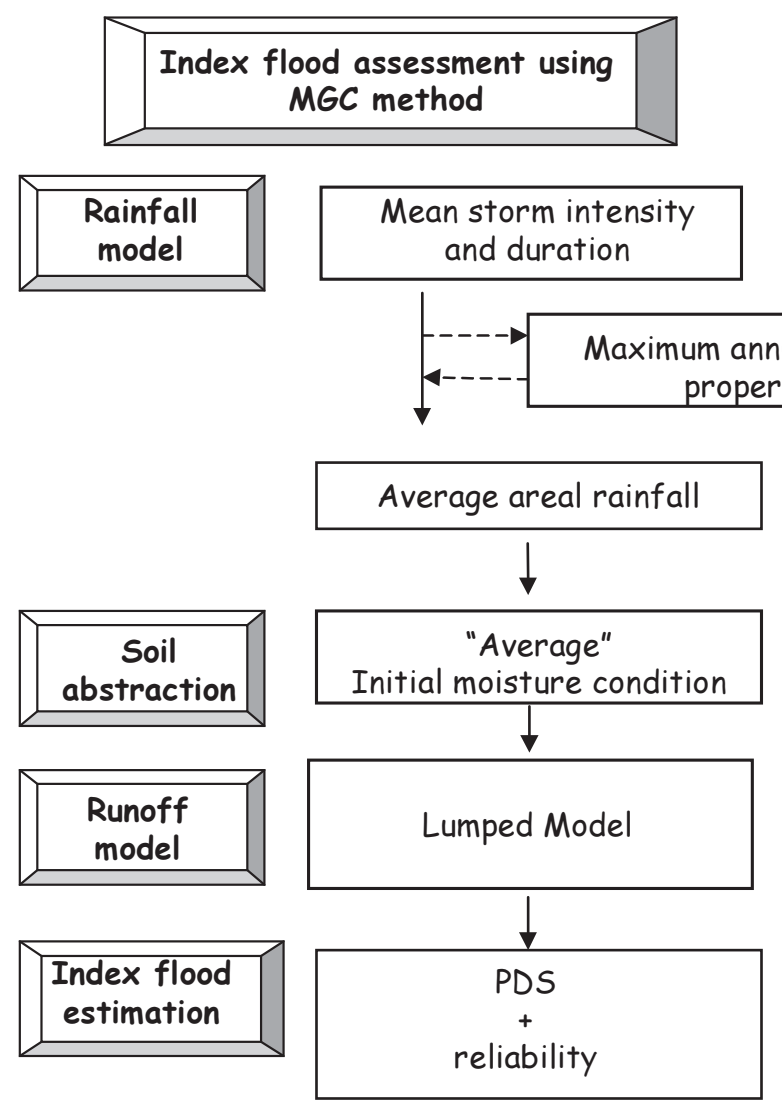

Fig. 2. Strategy for assessment of index flood using MGC method. Dashed line indicates eventual steps. First, the average storm duration and intensity for some gauged sites are required, eventually estimated from the maximum annual rainfall features. Then, the average area rainfall has to be evaluated. A proper moisture condition needs be defined to mimic the "average" soil abstraction. A lumped model needs be assessed correctly to simulate the basin response dynamics. The MGC method yields an estimate of the $q_{P D S}$ to be used for index flood estimation. A reliability check of the method (i.e. assessment of the index flood estimation variance) needs to be performed on observed flood series, considering both the PDS estimate and the final index flood estimate.

fixed temporal duration. This curve, referred to the centre of the storm, is expressed by a power law as:

$$
h(T)=a_{1} t^{v} x(T)
$$

where $h(T)$ is the $T$-year quantile of maximum annual rainfall depth for a duration of $t$ hours, $a_{1}$ (rainfall index, in mm hour-v, equal to the mean maximum annual hourly rainfall depth) and $n v$ (scaling exponent) are averaged over the drainage area commanded by the river gauging site and $x(T)$ is a frequency factor accounting for the return period. The expected, or index DDF curve, $h=a_{1} t^{v}$, coupled with soil abstraction and the basin response model, can be used to assess the $q_{\text {index }}$. Following this approach, account has to be taken of

- the reduction in the rainfall intensity passing from the point rainfall to the area rainfall through the area reduction factor, $K^{2}$.

- the variability of rainfall intensity within the storm duration; the design hyetograph has to reproduce the temporal variability of the observed hyetographs, if available.

The expected IDF curve, $i=h / t=a_{l} t^{\nu-1}$ referred to the centre of the storm, is transformed using the rational formula (e.g. Chow et al., 1988) into the expected value of maximum annual flood peaks, $q_{\text {index }}$ as follows:

$$
\hat{q}_{\text {index }}=\psi A i^{*}=\psi A h^{*} / \tau_{n c}
$$

where

- $A$ is the basin drainage area;

- $\tau_{n c}=\tau_{c}-\tau_{p}$ is the "net" storm duration, the difference between "critical" storm duration $t_{c}$, producing the 
maximum flood peaks and ponding time $t_{p}$;

- $\tau_{p}=I_{a} / i$ with $I_{a}=c S$, is the ponding time (Chow et al. 1988);

- $i^{*}=i^{*}\left(\tau_{c}\right)=h^{*}\left(\tau_{c}\right) / \tau_{n c}$ is the average of effective rainfall intensity for a storm of duration $\tau_{c}$, given by the ratio between the effective rainfall depth (or runoff volume per unit area) for a duration $\tau_{c}$ and the net duration;

- $\psi=\psi\left(q_{b} ; \tau_{n e}\right)$ is a reduction coefficient, where $q_{b}$ are basin parameters representing the geometry of the basin network (for instance, if the basin is modelled as a linear reservoir, the reduction factor is $\psi=1-e^{-\tau_{n c} / t_{L}}$ where $t_{L}$ is the basin lag time).

Using the SCS-CN method to transform the rainfall in runoff, the expected value of effective rainfall depth in Eqn. (15) can be determined using a second order second moment technique, SOSM (Adom et al., 1989) as:

$$
h^{*}=\frac{(h-c S)^{2}}{h+(1-c) S}+K^{2} V^{2} \frac{h^{2} S^{2}}{(h+(1-c) S)^{3}}
$$

where $S$ is the maximum soil potential retention, $c$ is the initial abstraction rate, $0 \leq c \leq 1, K^{2}$ is the areal reduction factor and $V$ is the coefficient of variation of the rainfall depth for a duration $\tau_{c}$. Note that a particularisation of Eqn. (15) for $c=0$, is given by Adom et al. (1989). The value of $\tau_{c}$ is determined from the condition:

$$
\tau_{c}: \tau=\tau_{c} \Rightarrow \max \left\lfloor\psi(\tau) A i^{*}(\tau)\right\rfloor .
$$

The rationale behind this method stems from the linearity among the net rainfall input and the runoff discharge when using a lumped model based on IUH theory. Because of such linearity, if one considers an impervious basin $(\mathrm{S}=0)$, the derived distribution of maximum annual flood peaks obtained from the DDF curves has the same dimensionless (i.e. normalised by the index value) distribution as the DDF curves (De Michele et al., 2000; Bocchiola et al., 2003). Therefore, the discharge calculated from the index DDF fits the average value of the derived distribution exactly. On this hypothesis, it seems reasonable to estimate the $q_{\text {index }}$ as the flood discharge associated with the index rainfall. When $\mathrm{S}>0$ (i.e. pervious basins), because of the non-linearity of the abstraction model, the derived discharges distribution changes its properties and the index rainfall does not provide the index flood (Bocchiola et al., 2003). However, the methodology can still be applied to obtain a first approximation to $q_{\text {index }}$. The method presents some uncertainties, concerning the transformation of the expected rainfall into the index flood, the hypothesis of a critical event, the approximations on the space-time variability of rainfall. The errors involved in index flood estimation based on expected storm scaling can rise to as much as $300 \%$ of the observed values, as verified by the authors in a preliminary study carried out on the Northern Italy territory. The sigma bounds for index flood estimation must be assessed on the basis of a calibration of the method for gauged basins in an homogeneous region (Brath et al., 1999). The straightforward applicability of this approach makes it suitable for a first approximation, when few local data or no data at all are available and a low reliability would be achieved by direct methods.

Monte Carlo simulation using stochastic rainfall input. Advanced simulation methods make use of stochastic simulation of rainfall random fields (e.g. Cowpertwait, 1994, 1995; Rahman et al., 2002) to perform Monte Carlo experiments. Accordingly, long time-series of rainfall data are generated at fine temporal resolutions, hourly or over a few minutes, using a stochastic model of temporal rainfall. If single site models are used, calibration is performed using the observed data series of area precipitation over the basin, obtained from processing available station data. When a multi-site model or a space-time model is used, one can produce multi-site synthetic rainfall series or spatially distributed rainfall fields. These synthetic data are used as input to the rainfall-runoff model. Since the rainfall input is continuous in time, the hydrological model requires the continuous revision of the soil moisture or its evaluation at the beginning of the storm event. The hydrographs corresponding to the rainfall input are determined and the series of annual flood peaks, $q{ }^{\prime}, \ldots, q{ }_{n}{ }_{n}$, is extracted. Then, the index flood is estimated as the overall mean of sample data either using Eqn. (1) or via the PDS approach in Eqns. (3)-(5). As an example, Rulli and Rosso (2002) showed that this method provided acceptable results for index flood estimation (error ranging from +10 to $+20 \%$ ) for the Bisagno river (Northern Italy), at two different sites, when compared with direct (AFS) and indirect (SOSM) methods. However, stochastic simulation requires sophisticated technology and extensive data handling, it is time consuming and requires skilled personnel for implementation. Although its use is still confined to advanced applications, this method may prove to be one of the most promising routes towards improving flood estimation. Again, the level of reliability of this method depends on several issues, from the rainfall generation model to soil abstraction and runoff modelling and cannot be assessed other than through numerical calibration in gauged basins in an homogeneous region. In particular, one should assess the sensitivity of the index flood estimate to the number of simulated years and to the different 


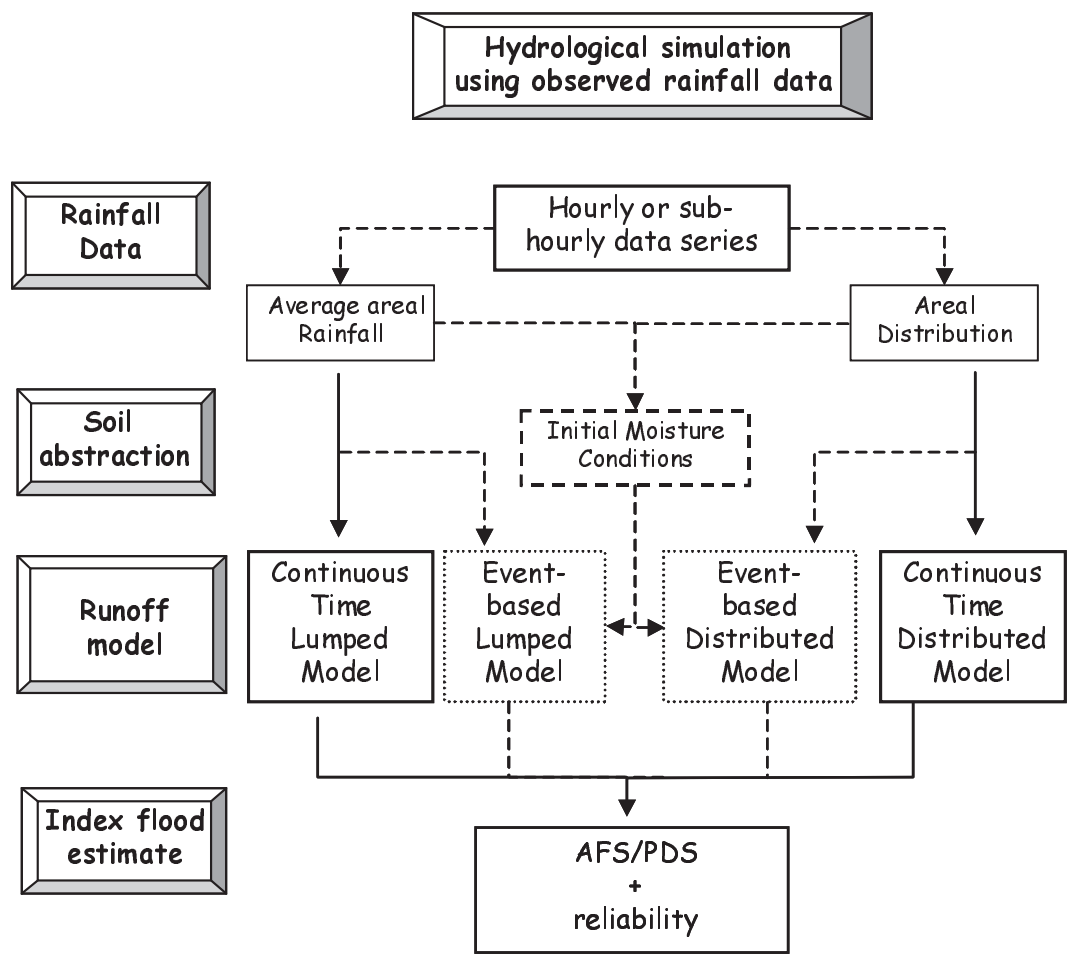

Fig. 3. Simulation strategy for assessment of index flood using observed rainfall data as input. Continuous lines refer to a continuous model, dashed lines refer to an event-based model. Firstly, one needs a series of observed rainfalls at gauged sites. If a lumped rainfall-runoff model is to be used, an average value of areal rainfall is necessary. Conversely, when using a distributed model, the rainfall areal distribution can be assessed and introduced as an input. The initial moisture condition at each storm event must be evaluated. This is done automatically in the framework of a continuous model, while an event based model requires an initial condition to be set by the investigator. The observed output series can be processed either via the AFS or the PDS approach. A reliability check of the method (i.e. assessment of the index flood estimation variance) must be performed on observed flood series.

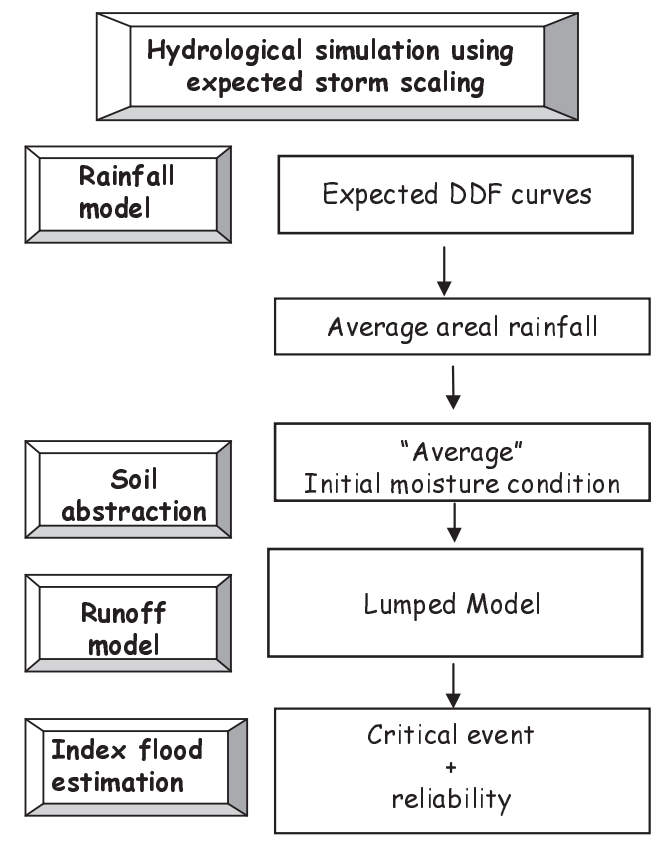

Fig. 4. Simulation strategy for assessment of index flood using expected storm scaling. Once index DDF is available, one has to evaluate the average areal rainfall. A proper moisture condition needs be defined to mimic the "average" soil abstraction. A lumped model must be assessed to simulate the basin response dynamics correctly. The storm event duration is set to provide the greatest flood peak, which is assumed to be the index flood. A reliability check of the method (i.e. assessment of the index flood estimation variance) must be performed on observed flood series. 


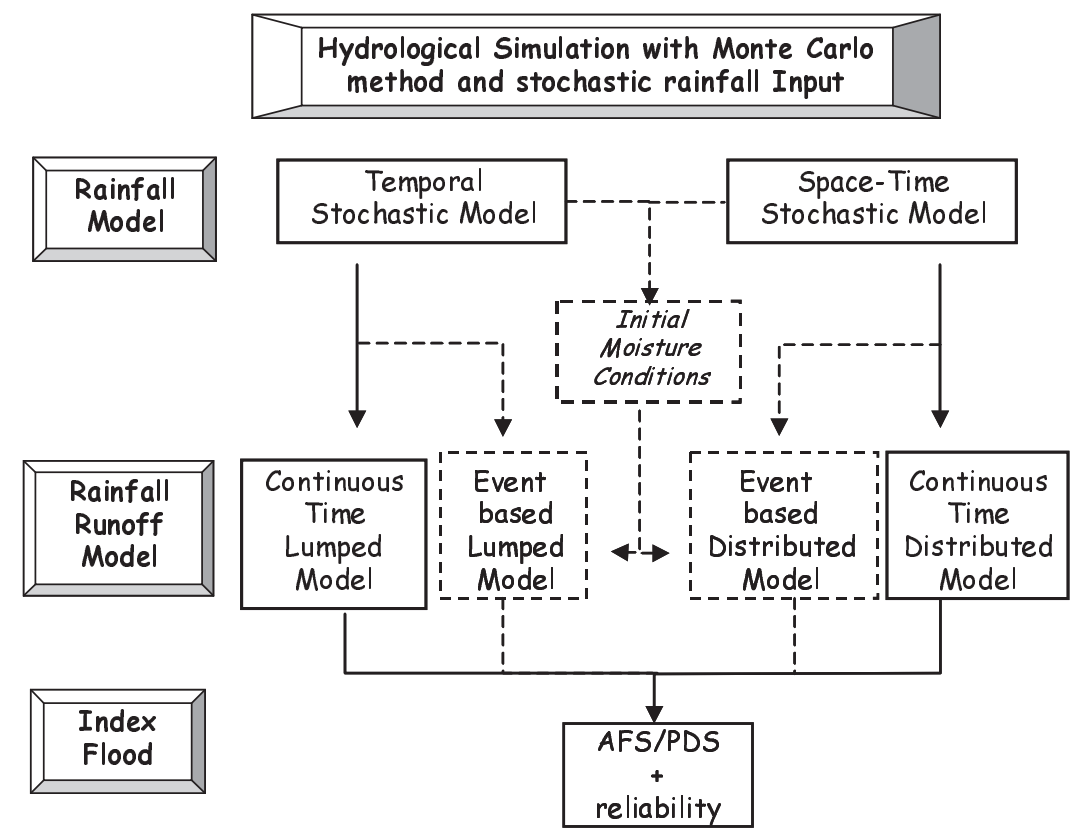

Fig. 5. Simulation strategy for assessment of index flood using Monte Carlo simulation methods with simulated rainfall input. Continuous lines refer to continuous model and dashed lines to the event-based model. Firstly, one needs a series of simulated rainfall data. If a lumped rainfall runoff model is to be used, an average areal rainfall is necessary. Conversely, when using a distributed model, the areal rainfall distribution can be assessed and introduced as an input to the model. The initial moisture condition at each storm event must be evaluated. This is done automatically in the framework of a continuous model, while a event based model requires an initial condition to be set by the investigator. The observed output series can be processed either via the AFS or the PDS approach. A reliability check of the method (i.e. assessment of the index flood estimation variance) must be performed on observed flood series.

simulated series and slight changes in the rainfall model parameter.

Flow-charts of simulation strategies. The combination of rainfall and rainfall-runoff data handling procedures and models yields a wide range of possible approaches to index flood estimation using hydrological simulation. The flowcharts presented as Figs. 3-5 provide guidelines for strategy planning of simulation methods, using observed rainfall input (Fig. 3), based on expected storm scaling (Fig. 4), and on Monte Carlo methods using stochastic rainfall input (Fig. 5).

\section{Scenarios for index flood assessment}

As far as index flood assessment is concerned, several scenarios are possible, depending on the information available on the river site and the related drainage basin. One of the ways to summarise these scenarios is as follows:

A. River-sites equipped with a streamflow gauging station,

B. River-sites in a gauged catchment,

C. River-sites located in an ungauged basin in an homogeneous region,
D. River-sites close to a dam or another impounding facility,

E. River-sites located at historical sites in urbanised ungauged basins.

In the index flood assessment exercise, it may be appropriate to implement one or more scenarios so that the method that best adapts to this scenario should be adopted. In Fig. 6, suitable methods are indicated for the scenarios considered, explained as follows:

A. Under the first scenario, index flood estimation can be approached using direct methods, that is evaluating $q_{\text {index }}$ from the observations, using either the AFS or the PDS method (De Michele and Rosso, 2001). The estimation variance can be assessed from Eqn. (2). If a 'short' series of the available records provides an estimation variance greater than that from some indirect method, it is more reliable to use the latter (De Michele and Rosso, 2000) or a weighted combination of different methods.

B. If the river site selected is in a gauged catchment, the value of index flood computed at the gauged site can be up- or down-scaled with basin area, following the 

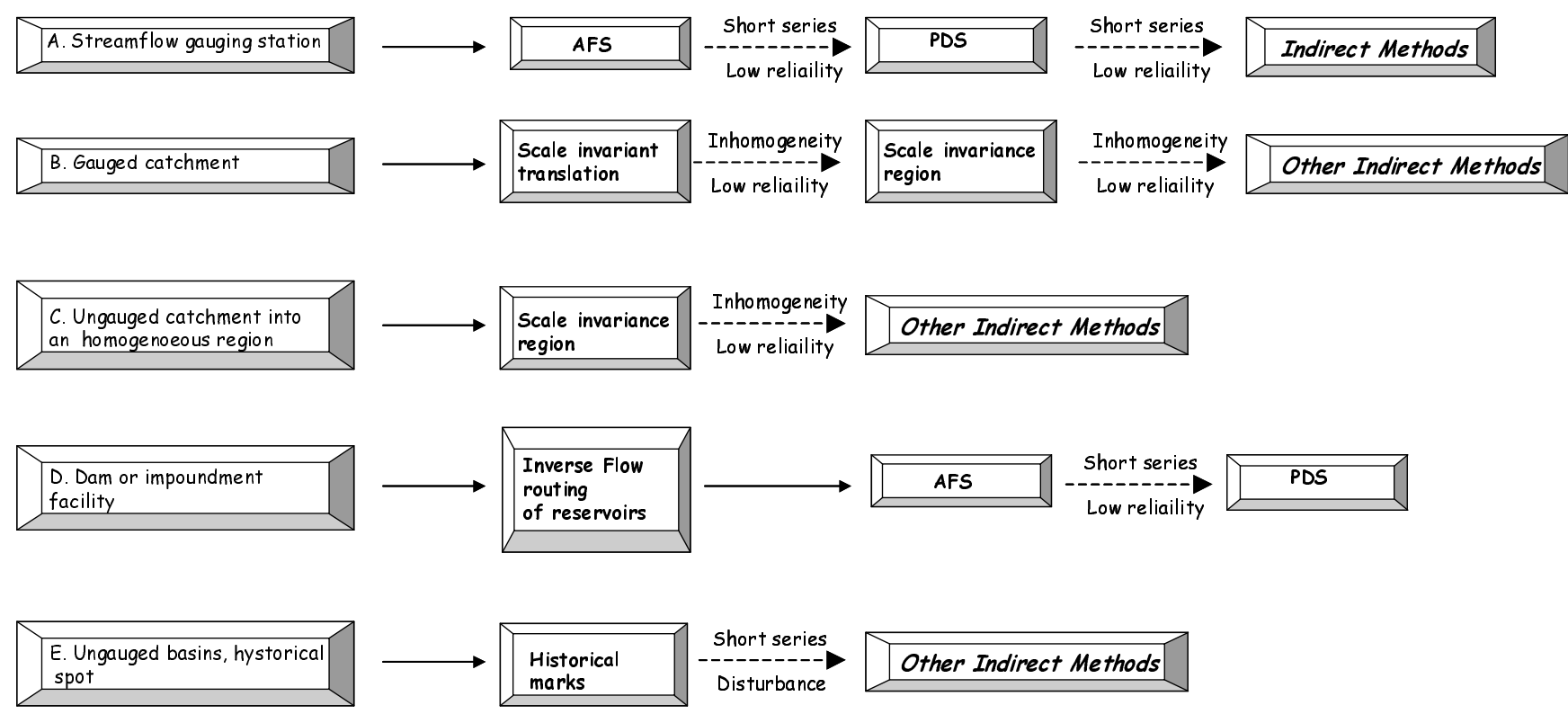

Fig. 6. Possible scenarios for index flood assessment at a given river site. The suggested methods are indicated in order of complexity.

concept of 'scale invariance' of index flood with drainage area in an homogeneous region ('scale invariant translation'). If $A_{g}$ is the drainage area at the gauged station and $A$ that at the ungauged one, this approach yields:

$$
\hat{q}_{\text {index }}(A)=q_{\text {index }}\left(A_{g}\right)\left(\frac{A}{A_{g}}\right)^{m}
$$

One can either use the regional scaling exponent $m$ or fit a scaling law to the drainage basin of interest, depending on data availability. Equation (18) holds if the drainage area lies in the range of validity of scale invariance. The validity of this approach depends also on the homogeneity of basin response as one moves throughout the river network (i.e. similar precipitation properties, land cover, morphological and dynamic characteristics). For instance, a non-homogeneous response can occur in basins with increasing urbanisation downstream. If more gauged stations are available in the same basin, one can re-scale the index flood observed either to the closest station or to the one which has the most similar behaviour, as illustrated above. The sigma bounds of the estimated values can be assessed from the tuning of the scaling law (determination coefficient $R^{2}$ ) in the river basin, if available, or in the homogeneous region. If a low reliability is expected, due to a strongly inhomogeneous response, one can estimate the index flood using indirect methods, including empirical formulae, the MGC method and hydrological simulation, the choice depending on the expected estimation variance. Note that hydrological data from neighbouring gauged streams can be used for model calibration and validation. The approach based on bankfull discharge can be used, provided the natural river path is neither modified by engineering works nor constrained by tectonic controls.

C. For a river site in the same homogeneous region as a gauged basin, the value of index flood can be assessed by the scale invariant approach, expressed by Eqn. (7), provided the drainage area lies in the range of validity of scale invariance. Furthermore, the validity of this approach depends on the homogeneity of basin responses in the homogeneous region (i.e. similar precipitation properties, land cover, morphological and dynamic characteristics). Alternatively, one can estimate the index flood using indirect methods. These include empirical formulas, the MGC method and hydrological simulation. Prior to its application, however, one should check on the reliability of the approach selected using hydrological data from similar gauged basins, i.e. from catchments in the same homogeneous region. Again, bankfull discharge can be used, provided the natural river course is unaltered.

D. The fourth scenario deals with river sites located next 
to an impounding facility, which provide some 'break' points in the hydraulic continuity of the river. As an example, in the Italian Dam Register (Registro Italiano Dighe), 551 dams are classified as large dams and about 1200 as small dams, most of them in Northern Italy. Most of them are long-term facilities built in the first part of the 20th century, with long operating records. Long-term series of continuous data on reservoir level and outflow are available with fine resolution, so undisturbed inflows can be evaluated by inverse reservoir routing (Bras, 1990, p. 475; De Michele et al., 1998). The simulated historical inflows can then be processed to obtain an index flood estimate based on the PDS or the AFS approach, depending on the availability of data as described previously. Scale invariant translation or regional scale invariance can be used if the reservoir is in the same basin as the river site, or in the same homogeneous region.

E. The last scenario deals with those ungauged river sites located in highly urbanised areas, or, more generally speaking, where historical flood marks allow a reliable threshold discharge to be determined and used for index flood estimation. The required data are often available from the literature and other information sources, while overflowing occurrences are fairly well documented. In such cases, historical flood mark analysis can provide accurate results. To effect this, one needs to assess the hydraulic geometry at the time of the particular episode, with particular care at those sites where the operation of previous engineering works, such as bridges, channels, flood diversion facilities, dikes and ponds, provides information about remodelling of water levels.

\section{Conclusions}

The paper reviews the recent advances in the estimation of index flood, defined as the expected value, or average, of the maximum annual flood peaks. Its assessment depends on the type and amount of information available at the site being investigated. Direct and indirect approaches have been discussed for the purpose, each featuring some degree of uncertainty. To choose the most reliable method, one needs to know the reliability associated with the statistical estimate, perhaps through an estimation variance, which would provide confidence limits of a fixed significance level. To give a theoretical framework for index flood assessment, a set of different scenarios is drawn, related to data availability. Each scenario is described and the most suitable methods are suggested, in increasing order of complexity and expected reliability. Indeed, more complicated situations could be faced than those included in the framework here proposed and manifold methods could be proposed, depending on the site selected and on the available information. The paper provides a comprehensive problemoriented approach to index flood assessment suitable for use as a 'cookbook' for research as well as for practical purposes.

\section{Acknowledgments}

This study has been carried in the context of UE project FRAMEWORK (contract ENV-CT97-0529) which had North-Western Italy as a key study area. It has benefited from discussions arising from joint case studies for Austria and Switzerland. The results presented here also benefited from research work carried out within the special programme on 'Flood Evaluation' (VAPI) by the National Group for Prevention from Hydrological Disasters (GNDCI) supported by the National Research Council (CNR) of Italy (contract n. 03.00065.GN42). The authors kindly acknowledge Prof. Josè D. Salas for providing precious criticism and suggestions in the review phase of the manuscript and for helping to cast it into a more readable format.

\section{References}

Adom, D.N., Bacchi, B., Brath, A. and Rosso, R., 1989. On the geomorphoclimatic derivation of flood frequency (peak and volume) at the basin and regional scale. In: New Directions for Surface Water Modeling, M.L. Kavvas, (Ed.) IAHS Publ. no. 181, 165-176.

Bacchi, B. and Rosso, R., 1988. Geo-morphoclimatic analysis of the of flood frequency regionalisation models. Proceedings: "XXI Congress of Hydraulics and Hydraulic Facilities", L'Aquila, 1, 15-27. (In Italian).

Bacchi, B., Rosso, R. and Adom, D., 1989. On the geomorphoclimatic derivation of flood frequency (peak and volume) at the basin region scale. In: New directions for surface water modeling, M.L. Kavvas, (Ed.) IAHS Publ. no.181,

Bocchiola, D. and De Michele, C., 2000. Data Collection for the Northern Italy Case Study. In: Framework, EC Environment and Climate Research Programme 1994-98, ENV4_CT97_0529, Hydrological and Hydrogeological Risks, Renzo Rosso, (Ed.), Partner 1, ANNEX 9.

Bocchiola, D., De Michele, C. and Rosso, R., 2000. Index flood discharge assessment by multi-regressive laws. In: Framework, EC Environment and Climate Research Programme 1994-98, ENV4_CT97_0529, Hydrological and Hydrogeological Risks, Edited by Renzo Rosso, Partner 1, ANNEX 10.

Bocchiola, D., De Michele, C. and Rosso, R., 2003. The derived distribution approach in assessing the iso-frequency of extreme floods and storms. Int. Proceedings Mathematical and statistical methods for hydrological series analysis (Metodi Statistici e Matematici per l'Analisi delle Serie Idrologiche, D.Piccolo and L. Umbertini (Eds.), 165-176. Roma, Italy, 9 May 2003.

Boughton, W. and Droop, B., 2003. Continuous simulation for design flood estimation - a review. Environ. Model. Software, 18, 309-318. 
Bocchiola, D., De Michele, C. and Rosso, R., 2003. Application of the generalized extreme values distribution GEV to regional analysis of floods in Italy. L'ACQUA, in press (in Italian).

Bras, R.L., 1990. Hydrology. Addison-Wesley, USA.

Brath, A., Bacchi, B. and Rosso, R., 1992. The geo-morphoclimatic derivation of the probability distribution of the flood discharge. Idrotecnica, 4, 183-200. (In Italian).

Brath, A. and Rosso, R., 1994. Flood evaluation in the Po Basin and in Thyrrenian Liguria. In: La Valutazione delle Piene in Italia, a cura di S. Gabriele and P Versace, Pubbl. CNR- GNDCI, Roma. (In Italian).

Brath, A., De Michele, C. and Rosso, R., 1996. An in direct conceptually based methodology for index flood assessment. Proceedings "XXV Congress of Hydraulic and Hydraulic facilities", Torino, 18-20 September, Vol.1, 52-63. (In Italian).

Brath, A., Castellarin, A., Franchini, M. and Galeati, G., 1999. Estimation of index flood through in direct methods. L'ACQUA, 6, 21-34. (In Italian).

Burlando, P. and Rosso, R., 1996. Scaling and multifractal DepthDuration-Frequency curves of storm precipitation. J. Hydrol., 187, 45-64.

Cameron, D.S., Beven, K.J., Tawn, J., Blazkovac, S. and Naden, P., 1999. Flood frequency estimation by continuous simulation for a gauged upland catchment (with uncertainty). J. Hydrol., 219, 169-187.

Chow, V.T., Maidment, D.R. and Mays, L.W., 1988. Applied hydrology. McGraw Hill, New York, USA.

CNR-GNDCI, 1998. MAPPAVI: Censimento delle aree italiane storicamente colpite da frane e da inondazioni. Versione 1.2, mappavi@gndci.pg.cnr.it, CNR-GNDCI.

Committee on Techniques for Estimating Probabilities of Extreme Floods, 1988. Techniques for Estimating Probabilities of Extreme Floods: Methods and Recommended Research. National Academy Press, Washington, D.C., USA.

Cordova, J.R. and Rodriguez-Iturbe, I., 1983. Geomorphoclimatic estimation of extreme flow probabilities. J. Hydrol., 65, 159173.

Cordova, J.R. and Rodriguez-Iturbe, I., 1985. On probabilistic structure of storm surface runoff. Water Resour. Res., 21, 755763.

Cowpertwait, P.S.P., 1994. A generalized point process model of rainfall. Proc. R. Soc. Lond., A 447, 23-37.

Cowpertwait, P.S.P., 1995. A generalized spatial-temporal model of rainfall based on a cluster point process. Proc. R. Soc. Lond., A 450, 163-175.

Darlymple, T., 1960. Flood frequency analysis. U.S. Geological Survey. Water Supply Paper 1543-A.

De Michele, C. and Rosso, R., 2000. Uncertainty Assessment of Regionalized Flood Frequency Estimates. In: FRAMEWORKFlash-flood Risk Assessment under the iMpacts of land use changes and river Engineering WORKs, First Annual Report, edited by R. Rosso, EC Contract ENV4-CT97-0529, Politecnico di Milano.

De Michele, C. and Rosso, R., 2001. Uncertainty assessment of regionalized flood frequency estimates. J. Hydrol. Eng., ASCE, 6, 453-459.

De Michele, C. and Rosso, R., 2002. A multi-level approach to flood frequency regionalization. Hydrol. Earth Syst. Sci., 6, 185194.

De Michele, C., Petaccia, A. and Rosso, R., 1998. Validation of regional models for statistic flood design via dams observation. Proceedings of the "XXVI Congress of Hydraulics and Hydraulic Facilities", Catania, 9-12 September. (In Italian).
De Michele, C., Rosso, R. and Salvadori, G., 2000. Scaling laws and derived distribution of maximum annual flood. In: Int. Symposium on River Defence, vol.1, F. Toensmann and M. Koch (Eds.) Kassel Reports of Hydraulic Engineering n. 9/2000, D103-D-116.

Dunne, T. and Leopold, L.B., 1978. Water in Environmental Planning. W. H. Freeman and Co., San Francisco, USA.

Eagleson, P.S., 1972. Dynamics of flood frequency. Water Resour. Res., 8, 878-898.

Eagleson, P.S., 1978. Climate, Soil and Vegetation. 5. A Derived Distribution of Storm Surface Runoff. Water Resour. Res., 14, 741-748.

Efron, B. and Tibshirany R.J., 1993. An introduction to the bootstrap. Chapman and Hall, London, UK.

Fisher, R.A. and Tippett, H.A., 1928. Limiting forms of the frequency distribution of the largest or smallest sample. Proc. Cambridge Phil. Soc., 24, 180-190.

Fréchet, M., 1927. Sur la loi de probabilité de l'ècart maximum. Annales de la Societé Polonaise de Mathématique Cracow, 6 , 93-117.

Fuller, W. E., 1914. Flood flows. Trans. ASCE, 77, 564-617.

Gnedenko, B.V., 1943. Sur la distribution limite du terme maximum d'une série aleatorie. Ann. Math., 44, 423-453.

Gumbel, E.J., 1958. Statistics of Extremes. Columbia University Press, New York, USA..

Gupta, V.K., Mesa, O.J. and Dawdy, D.R., 1994. Multiscaling Theory of flood peaks: regional quantile analysis. Water Resour. Res., 30, 3405-3421.

Hazen, A., 1914. Discussion on "Flood flows" by W.E. Fuller. Trans. ASCE, 77, 526-563.

Hebson, C. and Wood, E.F., 1982. A derived flood frequency distribution using Horton order ratios. Water Resour. Res., 18, $1509-1518$.

Hebson, C. and Wood, E.F., 1986. A study of scale effects on flood frequency response. In: Scale problems in Hydrology, V.K.Gupta, I. Rodriguez-Iturbe and E. F. Wood, (Eds.), Reidel, Boston, Mass., USA.

Hosking, J.R.M. and Wallis, J.R., 1993. Some statistics useful in regional frequency analyis. Water Resour. Res., 29, 217-281.

Hosking, J.R.M. and Wallis, J.R., 1997. Regional frequency analysis: an approach based on L-moments. Cambridge University Press, Cambridge, U.K.

Jenkinson, A.F., 1955. The frequency distribution of the annual maximum (or minimum) values of meteorological elements. Quart. J. Roy. Meteorol. Soc., 87, 158.

Kottegoda, N. and Rosso, R., 1997. Statistics, Probability and Reliability for Civil and Environmental Engineers. McGrawHill, New York, USA.

Leadbetter, M.R., Lindgren, G. and Rootzén, H., 1983. Extremes and Related Properties of Random Sequences and Processes. Springer, New York, USA.

Leopold, L.B., 1994. A view of the River. Harvard University Press. Cambridge, Mass., USA

Leopold, L.B., Wolman, M.G. and Miller, J.P., 1964. Fluvial Processes in Geomorphology. W. H. Freeman and Co. San Francisco, USA

Natural Environment Research Council, 1975. Flood Studies Report, Vol I. Hydrological Studies., NERC, London, UK.

Rahman, A., Weinmann, P.E., Hoang, T.M.T. and Laurenson, E.M., 2002. MonteCarlo simulation of flood frequency curves from rainfall. J. Hydrol., 256, 196-210.

Raines, T. H. and Valdes, J. B.,1993. Estimation of flood frequencies for ungauged catchments. J. Hydraul. Eng., 119, $1138-1155$. 
Ramachandra Rao, A. and Hamed, K. H., 2000. Flood Frequency Analysis. CRC Press, Boca Raton, USA.

Robinson, J.S. and Sivapalan, M., 1997. An investigation into the physical causes of scaling and heterogeneity of regional flood frequency. Water Resour. Res., 33, 1045-1059.

Rodriguez- Iturbe, I., 1993. The geomorphologic IUH. Channel Network Hydrology. Wiley, New York, USA.

Rodriguez-Iturbe, I., Gonzales-Sanabria, M. and Bras R.L., 1982. A geomorphoclimatic theory of the instantaneous unit hydrograph. Water Resour. Res., 18, 877-886.

Robson, A. and Reed, D., 1999. Flood Estimation Handbook (FEH), Vol. 3. Institute of Hydrology, Wallingford, UK

Rosso, R., 1984. Nash model relation to Horton order ratios. Water Resour. Res., 20, 914-920.

Rosso, R., Brath, A., Burlando, P., De Michele, C. and Mancini, M., 1996. Scale invariance of flood regime. L'Acqua, 5, 15-23. (In Italian).

Rulli, M.C. and Rosso, R., 2002. An integrated simulation method for flash-flood risk assessment: 1 . Frequency predictions in the Bisagno River by combining stochastic and deterministic methods. Hydrol. Earth Syst. Sci., 6, 267-283.
Salas, J.D., Ramirez, J.A. and Rosso, R., 1994. Determination of flood characteristics by physically based methods. In: Coping with Floods, Chapter 6, G. Rossi, N. Harmancioglu and V. Yevjevich, (Eds.) Kluwer Academic Publishers, Dordrecht. 77110.

Savenije, H. H.G., 2003. The width of a bankfull channel; Lacey's formula explained. J. Hydrol., 276, 176-183.

Soil Conservation Service, U.S. Department of Agriculture, 1973. A method for estimating volume and rate of run-off in small watersheds. Technical paper 149, U.S. Dept. of Agric., Washington D.C.

Soil Conservation Service, 1986. National Engineering Handbook, section 4, Hydrology. Rev. ed., U.S. Department of Agriculture, Washington D.C., U.S.A.

Sveinsson, O., Boes, G.B., Duane, C. and Salas, J.D., 2001. Population index flood method for regional frequency analysis. Water Resour. Res., 37, 2733-2748.

Wood, E.F. and Hebson, C., 1986. On hydrologic similarity: 1, derivation of the dimensionless flood frequency curve. Water Resour. Res., 22, 1549-1554.

U.S. Weather Bureau, 1958. Rainfall intensity-frequency regime. Technical Paper 29, Washington D.C. 